\title{
Gelling pectins from carrot leftovers extracted by industrial-enzymes with ultrasound pretreatment
}

\author{
Alondra M. Idrovo Encalada ${ }^{\mathrm{a}, 1}$, Carolina D. Pérez ${ }^{\mathrm{b}, 2}$, Lia N. Gerschenson ${ }^{\mathrm{a}, 2}$, Ana M. Rojas ${ }^{\mathrm{a}, 2}$, \\ Eliana N. Fissore ${ }^{\mathrm{a}, *, 2}$ \\ a Departamento de Industrias, ITAPROQ-UBA-CONICET, Facultad de Ciencias Exactas y Naturales, University of Buenos Aires, Ciudad Universitaria, C1428BGA, Ciudad \\ de Buenos Aires, Argentina \\ ${ }^{\mathrm{b}}$ Instituto de Tecnología de Alimentos (ITA), Instituto Nacional de Tecnología Agropecuaria (INTA), CC-77, B1708WAB, Morón, Province of Buenos Aires, Argentina
}

\section{Keywords:}

Pectin-enriched fractions

Carrot leftover

Ultrasound-industrial enzyme-assisted

extraction

Carotenoids

Calcium crosslinked gels

Chemical compounds

$\alpha$-carotene (PubChem CID: 4369188)

$\alpha$-tocopherol (PubChem CID: 14985)

Hemicellulase (PubChem CID: 9025-56-3)

$\beta$-carotene (PubChem CID: 5280489)

Lutein (PubChem CID: 5281243)

Pectin (PubChem CID: 441476)

\begin{abstract}
A B S T R A C T
Misshapen carrots were upgraded as orange-colored pectin-enriched fractions (PEFs) useful as gelling agents and containing $\alpha$ - and $\beta$-carotenes, lutein, and $\alpha$-tocopherol, by applying a green process consisting of an ultrasound (US) pretreatment $\left(12.27 \mathrm{~W} / \mathrm{cm}^{2}\right.$ power intensity) followed by stirring in citrate buffer ( $\mathrm{pH} 5.20$ ) either without or with an industrial enzyme (fungal and bacterial hemicellulases, and cellulase) commercialized as baking improvers. PEFs showed uronic acid (UA) contents between 39 and 51\% with low degree of methylesterification (DM, 37.2-48\%), 11-22\% degree of acetylation (DA), and a common molecular weight of 121,000-138,000 Da. The protein contents were $9.6-17.8 \%$. Only the use of fungal hemicellulase produced per se higher yield of the PEF obtained (10.4\%), in comparison to the non-US pretreated citrate buffer extracted pectins $(6.9 \%)$. The USpretreatment was the step that decisively produced high extractive yields $(\approx 20 \%)$, while there was not additional contribution of industrial enzymes. However, enzymes permitted to obtain PEFs with different gel characteristics. US-pretreated PEFs at $2.00 \% \mathrm{w} / \mathrm{v}$ in water showed the best rheological performances, forming calcium-crosslinked true gels, more structured and with higher elastic ( $\left.G^{\prime}\right)$ modulus than non-US pretreated isolated fractions, one of which did not gel, being then useful as functional additives for food formulation.
\end{abstract}

\section{Introduction}

In Argentina, 302,000 tons of carrots are produced per year in 9,500 ha. The largest percentage goes to the domestic market for fresh consumption, and a small proportion is destined to dehydration industry, while $0.5-1.5 \%$ is exported (Dansa, Bougardt, \& Nocera, 2017). Aesthetic defects such as misshapen, sizes outside standard, bifurcation, split, and pale roots with green shoulders led to an important (35\%) carrot discard (Alessandro, Lopez Frasca, \& Gonzalez, 2014). Supermarkets commercialize only straight carrots to facilitate the peeling in the full length. For instance, 25-30\% of all carrots produced in Yorkshire farms of United Kingdom are destined to animal feeding after checked by photographic sensor machines (Stuart, 2009). Color, other quality determinant, is caused by several pigments such as $\alpha$ - and $\beta$ carotenes, which also function as antioxidants, being vitamin A precursors (Stuart, 2009). Discarded carrots could be considered as a source of bioactive compounds such as soluble dietary fiber and antioxidants.

Pectin is a soluble dietary fiber listed among the ingredients of many food products due to its technological properties, mainly gelling and thickening capacities (Ciriminna, Fidalgo, Delisi, Ilharco, \& Pagliaro, 2016). Pectic polysaccharides are mostly constituted by D-galacturonic acid (GalA) that forms the homogalacturonan (HG) backbones of 1,4linked $\alpha$-D-GalpA, and significant amounts of $\mathrm{L}$-rhamnose alternating with GalA monomers, where the former sugar has lateral substitution by L-arabinose and D-galactose chains, forming the rhamnogalacturonan

\footnotetext{
Abbreviations: CP, carrot powder; DA, degree of acetylation; DM, degree of methylesterification; EAE, enzyme assisted extraction; UAE, ultrasound assisted ex-

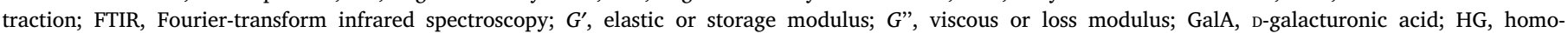
galacturonan; Mw, molecular weight; NS, neutral sugars; PEF, pectin-enriched fraction; RG-I, rhamnogalacturonan I; UA, uronic acids; US, ultrasound

* Corresponding author. Departamento de Industrias, Facultad de Ciencias Exactas y Naturales, University of Buenos Aires, Ciudad Universitaria, C1428BGA, Ciudad de Buenos Aires, Argentina.

E-mail address: eliana@di.fcen.uba.ar (E.N. Fissore).

${ }^{1}$ Fellow of CONICET.

${ }^{2}$ Member of CONICET.
} 
I (RG-I) core (Vincken et al., 2003). Also, RG-II can be found in pectins, which is constituted by rare monosaccharides such as 2-O-methyl fucose and 2-O-methyl xylose. Composition, structure, physiological and technological properties of pectin are influenced by the extraction conditions, as well as sources, location and other environmental factors. The degree of methylesterification (DM) is also a main factor that determines pectin functionality. Low (DM $<50 \%)$ and high (DM $>50 \%$ ) methoxylated pectins are able to produce thickening or gelling either in the presence of divalent ions such as calcium in the former case or of high concentrations of sucrose at acidic $\mathrm{pH}$ in the latter case (Van Buggenhout, Sila, Duvetter, Van Loey, \& Hendrickx, 2009). Commercial pectin is generally extracted from citrus and apple cell walls by treating the raw material with hot dilute mineral acid at $\mathrm{pH} 2$, generating large amounts of effluents that require treatment. Alternative extraction technologies such as enzyme assisted extraction (EAE) and ultrasound assisted extraction (UAE) have gained interest in the last decade due to the need for reducing or eliminating the use and generation of pollutant substances, as well as to obtain products with higher yields (Liew, Ngoh, Yusoff, \& Teoh, 2018).

EAE is based on the inherent ability of enzymes to catalyze reactions with high specificity and ability to function under mild processing conditions in aqueous solutions (Puri, Sharma, \& Barrow, 2012). Enzymes such as cellulases and hemicellulases degrade and disrupt the elastic cell wall network enabling the release of pectins with associated antioxidants. On the other hand, intense mechanical stirring at very high revolutions is also used to facilitate disruption for chemical and enzymatic extraction of dietary fibers (Rosicka-Kaczmarek, Komisarczyk, \& Nebesny, 2018). This procedure can be replaced by the effect of an UAE, which uses acoustic energy and low level of solvents to extract target compounds from various plant matrices (Freitas de Oliveira et al., 2016). An ultrasound (US) power intensity above $10 \mathrm{~W} /$ $\mathrm{cm}^{2}$ is required to produce cavitation and then transient bubbles, which are the main source of the chemical and mechanical effects of US-energy (Santos, Lodeiro, \& Capelo-Martínez, 2009).

The objective of the present work was to extract functional PEFs from smaller and misshapen carrots, which were stabilized as a sugarexhausted blanched-powder (CP). US-pretreatment for disruption of the cell wall enriched CP matrix followed by an enzyme attack for higher yields was the extractive process used. Industrial enzymes habitually commercialized for pentosans' hydrolysis in wheat dough were assayed. They included a cellulase produced by Trichoderma ressei, and two hemicellulases respectively obtained by fungal (Aspergillus niger) and bacterial (Bacillus subtilis) fermentation. PEFs obtained were then chemically characterized, and evaluated in their functional rheological performance to know their utility for food formulation. This information can help upgrade leftovers from carrot harvest and industrialization through the production of fractions with nutritional and food technological applications.

\section{Materials and methods}

\subsection{Chemicals}

Deionized water was used (MilliQ, Millipore, USA). D-galacturonic acid, $\alpha$-carotene, $\beta$-carotene, lutein, retinol, as well as $\alpha$-, $\beta$-, $\gamma$ - and $\delta$ tocopherol standards were from Sigma-Aldrich (Saint Louis, USA), while the other analytical grade chemicals were from Merck (Argentina's branch). The industrial enzymes used were from DSM (Netherlands), specifically BakeZyme Wholegrain (a cellulase from Trichoderma ressei, $1475 \mathrm{EGU} / \mathrm{g}$, active up to 50-65 ${ }^{\circ} \mathrm{C}$ ), HSP 6000 (a fungal endoxylanase from Aspergillus niger, $6000 \mathrm{EDX} / \mathrm{g}$, wide range $\mathrm{pH}$, inactivated above $65^{\circ} \mathrm{C}$ ), and BXP 5001 (a bacterial hemicellulase with the activity of a $\beta$-1,4-endoxylanase from Bacillus subtilis, $5000 \mathrm{NBXU} /$ $\mathrm{g}$, wide range $\mathrm{pH}$, inactivated above $65^{\circ} \mathrm{C}$ ).

EGU is the 1,4- $\beta$-endoglucanase activity. One EGU per gram is the amount of enzyme required to reduce the viscosity of a carboxymethylcellulose solution to one-half at $40^{\circ} \mathrm{C}$ and $\mathrm{pH}$ 6.0. On the other hand, one $\beta-1,4$-endoxylanase unit (EDX) is defined as the enzyme activity that creates a certain viscosity change in $1 \mathrm{~mL}$ of the reaction mixture under the conditions of the assay. It is based on the hydrolysis of the arabinoxylan substrate, resulting in a decrease of viscosity at $47^{\circ} \mathrm{C}$ and $\mathrm{pH} 2.75$. With respect to one NBXU, it is defined on $1 \%$ wheat arabinoxylan at $30^{\circ} \mathrm{C}, \mathrm{pH} 6.0$, and $30 \mathrm{~min}$ of incubation time. The xylose reducing residues are then measured with the reducing sugar assay. It is the amount of enzyme that can produce $0.5 \mathrm{mg}$ of xylose reducing residues in the incubation mixture.

\subsection{Carrot powder (CP)}

Carrot roots (Daucus carota L. var. Nantes) collected in Uco Valley (Mendoza, Argentina) and discarded after selection due to irregular shapes and sizes were used. Carrots were then washed, the petioles removed, and the rest of the carrot root was cut in slices and chopped (Moulinex FR6001, Argentina). Carrot tissue particles were dispersed in deionized water $(1: 4 \mathrm{w} / \mathrm{v})$ at room temperature, stirred at $600 \mathrm{rpm}$ and filtered through cheesecloth. The solid residue was recovered and the aqueous phase eliminated. This washing step was repeated other three times. The final solid residue was then stirred into $90^{\circ} \mathrm{C}$ deionized water for $5 \mathrm{~min}$ for enzyme inactivation, and then separated by filtration. This residue was freeze-dried (Christ, Germany; Pfeiffer vacuum pump, Germany), milled with a cutting mill (Wemir, Argentina), sealed under vacuum (Multivac C-200, Germany) into small Cryovac bags (Sealed Air, USA), and stored in darkness at $-18{ }^{\circ} \mathrm{C}$ until usage (CP).

Average particle size distribution of $\mathrm{CP}$ was performed for its characterization by sieving through a vibratory shaker (Retsch, Germany) as explained by Idrovo Encalada, Basanta, Fissore, De'Nobili, and Rojas (2016).

\subsection{Extractive procedure of PEFs from $C P$}

CP was submitted to the PEFs' isolation through the following steps: a) stirring in citrate buffer either without (control system) or with one of the enzymes above indicated (EAE); b) US-pretreatment followed by step (a).

\subsubsection{Buffer citrate for $E A E$}

For control system, a dispersion of $5.00 \mathrm{~g}$ of $\mathrm{CP}$ in $500 \mathrm{~mL}$ of $0.5 \mathrm{M}$ sodium citrate buffer ( $\mathrm{pH} \mathrm{5.20)}$ was stirred for $5 \mathrm{~h}$ or $24 \mathrm{~h}$ at $40^{\circ} \mathrm{C}$. For the $\mathrm{EAE}$, an aliquot of one of the enzymes above mentioned $(0,125 \mathrm{~g}$ of fungal or bacterial hemicellulase and $0,025 \mathrm{~g}$ of cellulase per gram of $\mathrm{CP}$ ) was added to the respective dispersion of $\mathrm{CP}$ in the citrate buffer (5.00 g:500 mL), and continuously stirred for $5 \mathrm{~h}$ or $24 \mathrm{~h}$ at $40^{\circ} \mathrm{C}$.

After buffer (control system) or EAE, each dispersion was filtered, the supernatant separated in a glass beaker and then precipitated by addition of $96 \% \mathrm{v} / \mathrm{v}$ ethanol $(1: 2 \mathrm{v} / \mathrm{v})$. It was left overnight at $8{ }^{\circ} \mathrm{C}$ for precipitation of the PEF, which was then recovered through vacuum filtration. The isolated PEF was washed with ethanol, filtrated, and finally freeze-dried, milled, sealed under vacuum and stored as previously indicated for $\mathrm{CP}$.

\subsubsection{US-pretreatment}

A $20 \mathrm{kHz}$ ultrasonic processor (Vibracell ${ }^{\circ}, 750$ Watt, Sonics Materials Inc, USA) was used. An $80 \%$ of wave-amplitude was selected with $5 \mathrm{~s}$ "on" followed by $5 \mathrm{~s}$ "off" pulses, and a 13-mm diameter titanium flat tip probe was used. CP (5.00 g) was dispersed in $500 \mathrm{~mL}$ of $0.5 \mathrm{M}$ sodium citrate buffer ( $\mathrm{pH} 5.20$ ). A $90-\mathrm{mm}$ internal diameter and 125-mm height beaker (Borosilicate glass, IVA, Argentina) was used as container. The liquid reached a height of $90 \mathrm{~mm}$ into the glass beaker, while the ultrasound probe was $20-\mathrm{mm}$ immersed. The dispersion was sonicated for a net time of $20 \mathrm{~min}$, and the temperature was determined as a function of time through a thermocouple attached to the US processor. The energy and power displayed by the equipment were also 
recorded. Afterwards, the dispersion was maintained under magnetic stirring for $5 \mathrm{~h}$ or $24 \mathrm{~h}$ at $40^{\circ} \mathrm{C}$ constant as explained in section 2.3.1. The extraction yield was calculated for each PEF and expressed on $\mathrm{CP}$ dry basis. Experiments were carried out in triplicate.

To calculate the energy and power actually provided by the equipment, temperature was also recorded in a separated experiment performed as explained above, but where the whole system was maintained thermally isolated, in a calorimetric assay (Mamvura, Iyuke, \& Paterson, 2018). Since the US radiation of a liquid produces heat, by recording the temperature as a function of time into an isolated system leads to the energy $(E$ ) estimation (in $J$ ) by the equation:

$d E=m \cdot c_{P} \cdot d T$

and to the power $(P)$ calculation (in $\mathrm{W}$ ):

$P=m \cdot c_{\mathrm{P}} \cdot d T / d t$

where $m$ is the total mass $(\mathrm{g})$ sonicated, $\mathrm{c}_{\mathrm{P}}$ is the heat capacity of water $\left(\mathrm{J} \cdot \mathrm{g}^{-1} \cdot \mathrm{C}^{-1}\right), T$ is the temperature (C) recorded at time $t$ (s) of effective sonication, and $d T / d t$ is the rate of temperature change. The assay was performed in triplicate. Power intensity was calculated from eq. (2), being indicated in W per unit area of the emitting surface or probe (W/ $\mathrm{cm}^{2}$ ). Efficiency was calculated as the ratio between the calculated power and the power displayed by the equipment.

\subsection{Color}

The lightness ( $L^{*}=0 \%$ black, $100 \%$ white), $a^{*}$ ( $-a^{*}$ greenness; $+a^{*}$ redness) and $b^{*}$ (- $b^{*}$ blueness; $+b^{*}$ yellowness) CIELab color parameters were evaluated for each PEF, as explained by Idrovo Encalada et al. (2016). A colorimeter (Minolta CM-600D, Tokyo, Japan) provided with a $1.5 \mathrm{~cm}$-diameter aperture, using a D65 standard illuminant and a $2^{\circ}$ standard observer was used. The average and standard deviation for samples' triplicates was reported for each parameter.

\subsection{Gel permeation chromatography (GPC)}

The molecular weight (Mw) of the PEFs was estimated using GPC according to Munarin, Bozzini, Visai, Tanzi, and Petrini (2013), with some modification. Aliquots of PEFs were dissolved in $0.1 \mathrm{M} \mathrm{NaNO}_{3}$ aqueous solution $(0.25 \% \mathrm{w} / \mathrm{w})$, and left overnight under stirring at ambient temperature. A GPC chromatograph (Waters System, USA) equipped with a heater (TCM $5 \mathrm{CH}$, Singapore), a pump, a refractive index detector (Waters 2414), and a DAD diode array detector (Waters 2998) was used, provided with a $100 \mu \mathrm{L}$ loop connected in series to a Ultrahydrogel pre-column $(60 \times 40 \mathrm{~mm})$, and two Ultrahydrogel $(500$ and $1000 \mathrm{~mm}$ ) columns. A $0.1 \mathrm{M} \mathrm{NaNO}_{3}$ solution was used as the mobile phase $(0.6 \mathrm{~mL} / \mathrm{min})$ at $40^{\circ} \mathrm{C}$. Seven dextrans (PSS kit, Waters, Germany) with $\mathrm{Mw}$ between 5,200 and 668,000 Da were used as standards for calibration. Samples were filtered $(0.22 \mu \mathrm{m}$ nylon) prior to injection into the GPC. Data were analyzed through the Breeze software (Empower 2, Sweden). Runs were performed in triplicate.

\subsection{Chemical analyses}

The $\mathrm{CP}$ and each $\mathrm{PEF}$ were analyzed in their respective protein, total carbohydrates' and uronic acid (UA) contents, DM (\%, molar ratio) and degree of acetylation (DA, \% molar ratio), according to the methods reported by Fissore, Ponce, Stortz, Rojas, and Gerschenson (2007). The DM and DA were calculated as the percent ratio between methanol or acetyl moles and moles of GalA in a given sample, respectively (Broxterman, Picouet, \& Schols, 2017). The neutral sugars' (NS) content was calculated as the arithmetical difference between the total carbohydrates' (polysaccharides) and the UA contents. The NS/UA is the ratio between the moles of NS and moles of UA. Moles of NS were calculated with a weighed mean monosaccharide molar mass of
$166.73 \mathrm{~g} / \mathrm{mol}$ by considering a typical monosaccharide composition of pectins like that of the citrate buffer extracted pectin previously determined by Fissore et al. (2007), as well as a NS/UA molar ratio of 1.2, typical of pectins (Basanta, de Escalada Pla, Stortz, \& Rojas, 2013). The monosaccharide composition of pectins considered was rhamnose $(\mathrm{Mw}=164.2 \mathrm{~g} / \mathrm{mol}) 16 \mathrm{~mol} / 100 \mathrm{~mol}$, arabinose $(\mathrm{Mw}=150 \mathrm{~g} / \mathrm{mol})$ $40 \mathrm{~mol} / 100 \mathrm{~mol}$, galactose $(\mathrm{Mw}=180.2 \mathrm{~g} / \mathrm{mol}) 30 \mathrm{~mol} / 100 \mathrm{~mol}$, $\mathrm{xy}-$ lose $(\mathrm{Mw}=150 \mathrm{~g} / \mathrm{mol}) 2 \mathrm{~mol} / 100 \mathrm{~mol}$, fucose $(\mathrm{Mw}=164.2 \mathrm{~g} / \mathrm{mol})$ $1 \mathrm{~mol} / 100 \mathrm{~mol}$, mannose $(\mathrm{Mw}=180.2 \mathrm{~g} / \mathrm{mol}) 1 \mathrm{~mol} / 100 \mathrm{~mol}, 2-\mathrm{O}$ methyl fucose $(\mathrm{Mw}=178 \mathrm{~g} / \mathrm{mol}) 2 \mathrm{~mol} / 100 \mathrm{~mol}$, 2-O-methyl xylose $(\mathrm{Mw}=164 \mathrm{~g} / \mathrm{mol}) \quad 2 \mathrm{~mol} / 100 \mathrm{~mol}, \quad$ glucose $\quad(\mathrm{Mw}=180.2 \mathrm{~g} / \mathrm{mol})$ $7 \mathrm{~mol} / 100 \mathrm{~mol}$.

Total carbohydrates' content was determined through the phenolsulfuric acid photometric method using D-galacturonic acid as standard. For analysis of $\mathrm{CP}$, the content of reducing carbohydrates was also determined through the Somogyi-Nelson method, using D-glucose as standard. Cellulose, lignin and non-cellulosic polysaccharides' contents were also determined for CP as reported by Basanta et al. (2013).

Fat soluble vitamins and similar compounds (carotenes', lutein, retinol, tocopherol isomers' contents) were evaluated according to the methodology described by Rossetti et al. (2010), which included a first step of saponification $\left(30 \mathrm{~min} ; 70^{\circ} \mathrm{C}\right)$ with $10 \mathrm{~N} \mathrm{KOH}$, and quantification through high performance liquid chromatography (HPLC).

All chemical analyses were performed in triplicate.

\subsection{Fast fourier transformed infrared spectroscopy (FTIR)}

Transmission spectra were recorded from $\mathrm{KBr}$ pellets of $\mathrm{CP}$ and PEFs extracted $(1 \% \mathrm{w} / \mathrm{w})$ through 64 scans performed between 4500 and $525 \mathrm{~cm}^{-1}$ with a resolution of $4 \mathrm{~cm}^{-1}$, using a Nicolet 8700 (Thermo Scientific Nicolet, MA, USA) spectrometer. Spectra were analyzed through the OMNIC software (version 7.3, Thermo Electron Corp., USA).

\subsection{Oscillatory assays}

Oscillatory shear rheometry was used for recording the mechanical spectra at $20.0^{\circ} \mathrm{C}$ of each PEF, in triplicate. Each PEF was dissolved by heating $\left(70{ }^{\circ} \mathrm{C}\right)$ in deionized water $(2.00 \% \mathrm{w} / \mathrm{v})$ and $\mathrm{CaCl}_{2}$ solution was added at enough proportion for gelling $\left(30 \mathrm{mg} \mathrm{Ca}^{2+} / \mathrm{gUA}\right)$, according to that previously determined by Fissore, Rojas, Gerschenson, and Williams (2013). The storage or elastic $\left(G^{\prime}\right)$ and loss or viscous ( $\left.G^{\prime \prime}\right)$ moduli as well as the tangent of the phase angle ( $\tan$ delta $\left.=G^{\prime \prime} / G^{\prime}\right)$, were recorded as a function of the angular frequency $(\omega)$ between 0.1 and $100 \mathrm{rad} / \mathrm{s}$, at a constant strain value chosen from the linear viscoelastic range of the amplitude sweeps previously carried out.

Amplitude sweeps were formerly performed to determine the linear viscoelastic range where a linear relationship between the stress and strain exists. The storage or elastic modulus $\left(G^{\prime}\right)$ and strain were then recorded as a function of the stress, at $1 \mathrm{~Hz}$ of constant frequency.

The assays described were performed with an MCR300 Paar Physica shear rheometer (Anton Paar, Austria) provided with a 25-mm-diameter serrated parallel plate (PP25/S) geometry. Temperature was maintained constant at $20.0^{\circ} \mathrm{C}$ through a Peltier system. A gap size of $1000 \mu \mathrm{m}$ was set. Data were recorded at steady-state.

\subsection{Statistical analyses}

The results are reported as the average and standard deviation (SD) for $n$ replicates. Statistical analyses of results were performed through an ANOVA ( $\alpha$ : 0.05) followed by the Tukey's significance difference test. The GraphPad Prism software (version 5.00, 2007, USA) was used. 


\section{Results and discussion}

\subsection{PEFs obtained from $C P$ of discarded carrots}

The fresh carrot tissue cut in 1-2 mm particles was washed with deionized water to eliminate simple sugars, and then blanched by immersion in water at $90{ }^{\circ} \mathrm{C}$ for enzyme-inactivation and increased availability of carotenes. CP was obtained with a $6.9 \%$ of yield on raw (fresh) carrot basis, and was applied to the extraction of the PEFs. Almost $61 \%$ and $19 \% \mathrm{w} / \mathrm{w}$ of the CP had 420 and $210 \mu \mathrm{m}$ average particle sizes, respectively, while $10 \%$ showed 105 and $53 \mu \mathrm{m}$ particle sizes.

CP chemical composition demonstrated that it was constituted by cell wall polysaccharides, which included non-cellulosic carbohydrates $(60.5 \% \mathrm{w} / \mathrm{w})$, cellulose $(10.1 \%)$, and remaining starch $(0.72 \%)$. The non-cellulosic carbohydrates accounted for the UA content $(14.0 \%)$ of the HG of pectins (DM 61.9\%), and the NS content (46.4\%) of pectins and hemicelluloses, the latter calculated as the arithmetical difference between the total carbohydrate content and the UA content. Reducing carbohydrates were not detectable. Lignin (4.2\%) and proteins $(5.9 \%)$ were determined as well.

When the CP was submitted to the US-power intensity of $12.27 \mathrm{~W} /$ $\mathrm{cm}^{2}$ as a pretreatment (Table 1) in the citrate buffer $(5 \mathrm{gCP}: 500 \mathrm{~mL}$ buffer), followed by stirring for $5 \mathrm{~h}$ in this buffer for control system, or after addition of an enzyme (either fungal hemicellulase, bacterial hemicellulase or cellulase), the yield increased significantly $(p<0.05)$ between 1.5 and four times (Table 2). The highest yields were obtained by UAE of fiber fractions with bacterial hemicellulase, cellulase or citrate buffer. Only the use of fungal hemicellulase produced per se an increase in the fiber product yield when compared to the non-US pretreated CP (10.4\%) (Table 2).

Increasing the stirring time up to $24 \mathrm{~h}$ after the US-pretreatment did not change the yields obtained through $5 \mathrm{~h}$ of stirring. Hence, the results are not reported in Table 2.

The PEFs obtained were constituted by some proteins (9.6-17.8\%), while the rest were total-carbohydrates of polysaccharides (99-83\% w/ w) (Table 2). The latter included the determined UA content of pectins (39-51.3\%) and the calculated NS content (35.5-58\%). The UAs were of low DM ( $<50 \%$ molar ratio), which decreased significantly $(p<0.05)$ in the US-pretreated fungal hemicellulase and cellulase fiber products (Table 2). The DA of the PEFs was relevant (11-22\% molar ratio). The galacturonyl residues of pectins can carry acetyl groups on $O-2$ and $O-3$ (Vincken et al., 2003) and, particularly, Broxterman et al. (2017) also found that pectins from unprocessed carrots showed a DA of $\approx 20 \%$. In our work, some lower DA is shown by

Table 1

Energy and power values displayed by the ultrasonic equipment and those calculated from the temperature-time records determined in the CP dispersions ${ }^{\mathrm{a}}$ adiabatically isolated. Efficiency, power intensity and density are also summarized.

\begin{tabular}{ll}
\hline $20 \mathrm{kHz}, 80 \%$ amplitude, $20 \mathrm{~min}$ & \\
\hline $\begin{array}{l}\text { Temperature range recorded during assays performed for the extraction } \\
\quad \text { of each PEF }\left({ }^{\circ} \mathrm{C}\right)\end{array}$ & $20-60$ \\
Temperature range recorded adiabatically $\left({ }^{\circ} \mathrm{C}\right)$ & $20-61$ \\
Energy $^{\mathrm{b}}$ calculated for the treatment $(\mathrm{J})$ & 78178 \\
Power & \\
Power intensity calculated $\left(\mathrm{W} / \mathrm{cm}^{2}\right)$ & 65.15 \\
Efficiency calculated $(\%)$ & 12.27 \\
Energy displayed by the device $(\mathrm{J})$ & 75.8 \\
Power displayed by the device $(\mathrm{W})$ & 63901 \\
\end{tabular}

a $5 \mathrm{~g} \mathrm{CP} / 500 \mathrm{~mL}$ citrate buffer ( $\mathrm{pH} 5.20$ ).

b Calculated according to equation (1) for a $13 \mathrm{~mm}$-diameter ultrasound tip probe, and the sample container dimensions reported, using the temperatures recorded to $20 \mathrm{~min}$ of US treatment at adiabatic conditions.

c Calculated according to equation (2).
PEFs extracted through bacterial hemicellulase and, especially, by USpretreated/cellulase.

The NS/UA molar ratio calculated by considering a weighed mean monosaccharide molar mass of $166.73 \mathrm{~g} / \mathrm{mol}$ of a typical monosaccharide composition of pectins, varied between 0.81 and 1.43 (Table 2). These ratios are those regularly found in pectins (Basanta et al., 2013). Pectins are constituted by HG blocks of GalA monomers alternating with the RG-I short chains. As mentioned, rhamnosyl residues can be substituted at $O-4$ with arabinogalactan, arabinan and/or galactan side chains, all constituting the NS components of pectins (Vincken et al., 2003).

After comparison with the PEF yield obtained by extraction in citrate buffer with US-pretreatment (20.6\%; Table 2), it can be concluded that probably there was not additional contribution of the industrial enzyme-activities to achieve higher yields in the extractive processes.

\subsection{FTIR analysis of the pectin-fractions isolated from $C P$}

The FTIR spectra recorded from the PEFs are shown in Fig. 1. The broad band at $\approx 3403 \mathrm{~cm}^{-1}$ is ascribed to the $-\mathrm{OH}$ groups' stretch of pectins, while the short bands at 2904 and $2831 \mathrm{~cm}^{-1}$ correspond to the $\mathrm{C}-\mathrm{H}$ stretch. The $1722-1733 \mathrm{~cm}^{-1}$ small peak is attributed to the $\mathrm{C}=\mathrm{O}$ stretch of the esterified carboxyl group, which is noticeable smaller than the neighbor band observed at $1605-1596 \mathrm{~cm}^{-1}$, ascribed to the anti-symmetric ionized carboxylate stretch (Purcell \& Fishman, 1987). This is typical of low methoxyl pectins like those herein extracted (Table 2). The symmetric free carboxylate group stretch is instead observed at $\approx 1412 \mathrm{~cm}^{-1}$, where the fingerprint region begins (Fig. 1). The band at $1605-1596 \mathrm{~cm}^{-1}$ widens further $\approx 1540 \mathrm{~cm}^{-1}$ and down to $1488 \mathrm{~cm}^{-1}$, which can be ascribed to the masked small band at 1520 or $1515 \mathrm{~cm}^{-1}$ corresponding to the typical absorption of the aromatic ring of feruloylated pectins (Synytsya, Copikova, \& Jankovska, 2003). This part of the spectra coincided with that of the CP spectrum where a small band can be observed in the same region, together with a narrow band at $1622 \mathrm{~cm}^{-1}$ that corresponds to the stretching of the ionized carboxylate (Fig. 1). Ng, Parr, Ingham, Rigby, and Waldron (1998) found trans- and cis-ferulic acid, 8-O-4'-diferulic acid, and lower amounts of 5,8'-diferulic acid in the cell walls of carrots.

The fingerprint zone between 1420 and $1225 \mathrm{~cm}^{-1}$, ascribed to the $\mathrm{C}-\mathrm{O}-\mathrm{H}$ bending and $\mathrm{C}-\mathrm{O}$ stretch vibrations, and the broad band with some typical peaks of the polygalacturonic acid backbone of pectins such as those at $1133,1087,1012$, and $945 \mathrm{~cm}^{-1}$ can be observed (Fig. 1).

\subsection{Functional properties of the extracted PEFs}

\subsubsection{Rheological properties}

Since all PEFs studied were of low DM (Table 2), their rheological performances in water were determined in the presence of calcium ions ( $30 \mathrm{mg} / \mathrm{g} \mathrm{UA}$ ). As can be observed from the mechanical spectra recorded at $20.0{ }^{\circ} \mathrm{C}$ in three decades of angular frequency $(\omega)$ from their respective aqueous solution $(2.00 \% \mathrm{w} / \mathrm{v})$, true gels were obtained from all US-pretreated PEFs, together with higher elastic $\left(G^{\prime}\right)$ modulus values (Fig. 2a,b,c,d). According to this kind of viscoelastic material, the tangent of the delta angle was lower than 1. Higher frequency dependence of the tangent of delta angle can be easily observed in the case of the buffer extracted PEF without US pretreatment (Fig. 2a). The mechanical spectra of the US-pretreated fractions were also notably less frequency dependent, especially the viscous modulus ( $G$ '), than the mechanical spectra of non-US extracted PEFs, indicating more structured systems in water for the former systems. Particularly, the non-ultrasounded fiber fraction obtained by digestion with fungal hemicellulase in citrate buffer produced the mechanical spectrum of a dilute solution when present at $2.00 \% \mathrm{w} / \mathrm{v}$ concentration, since $G$ " was always above $G^{\prime}$ in the frequency range swept, and it was strongly dependent on frequency 
Table 2

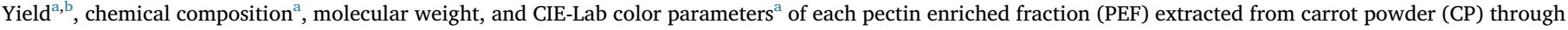

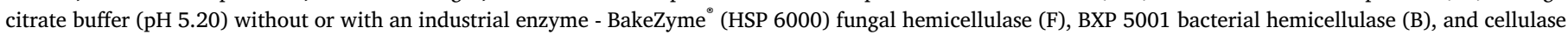
(Wholegrain) -, without or with ultrasound (US) pretreatment (12.27 W/ $\mathrm{cm}^{2}$ power intensity).

\begin{tabular}{|c|c|c|c|c|c|c|c|c|}
\hline & Buffer pH 5.20 & $\begin{array}{l}\text { Buffer pH } \\
5.20+\text { US }\end{array}$ & Hemicellulase F & $\begin{array}{l}\text { Hemicellulase } \\
\mathrm{F}+\mathrm{US}\end{array}$ & Hemicellulase B & $\begin{array}{l}\text { Hemicellulase } \\
\mathrm{B}+\mathrm{US}\end{array}$ & Cellulase & Cellulase + US \\
\hline Yield $^{\mathrm{a}, \mathrm{b}}(\mathrm{g} / 100 \mathrm{~g} \mathrm{CP})$ & $6.9 \pm 0.4^{\mathrm{A}, \mathrm{E}}$ & $20.6 \pm 0.7^{\mathrm{B}}$ & $10.4 \pm 0.9^{\mathrm{C}}$ & $15.7 \pm 0.7^{\mathrm{D}}$ & $8.3 \pm 0.7^{\mathrm{A}}$ & $18 \pm 3^{\mathrm{B}}$ & $5.5 \pm 0.7^{\mathrm{E}}$ & $20 \pm 3^{\mathrm{B}}$ \\
\hline Proteins $^{\mathrm{a}}$ (g/100 g PEF) & $11 \pm 2^{\mathrm{A}, \mathrm{B}}$ & $11 \pm 0.1^{\mathrm{A}}$ & $9.6 \pm 0.4^{C}$ & $17.8 \pm 0.6^{\mathrm{A}}$ & $13.2 \pm 0.9^{\mathrm{C}}$ & $15.1 \pm 0.2^{\mathrm{C}}$ & $12.7 \pm 0.2^{\mathrm{D}}$ & $13 \pm 1^{\mathrm{B}}$ \\
\hline $\begin{array}{l}\text { Total carbohydrates }{ }^{\mathrm{a}} \text { (g/ } \\
100 \mathrm{~g} \text { PEF) }\end{array}$ & $97 \pm 2^{\mathrm{A}}$ & $83 \pm 3^{B}$ & $89 \pm 2^{\mathrm{A}}$ & $85 \pm 3^{\mathrm{A}}$ & $89 \pm 1^{\mathrm{A}}$ & $89 \pm 5^{\mathrm{A}}$ & $91.3 \pm 0.4^{B}$ & $90 \pm 4^{B}$ \\
\hline $\begin{array}{l}\text { Uronic acids }{ }^{\mathrm{a}} \text { (UA) (g/100 g } \\
\text { PEF) }\end{array}$ & $42.2 \pm 0.9^{\mathrm{A}, \mathrm{B}}$ & $39 \pm 3^{\mathrm{B}}$ & $51.3 \pm 0.4^{\mathrm{C}}$ & $49.5 \pm 0.8^{\mathrm{C}, \mathrm{D}}$ & $48 \pm 1^{\mathrm{D}, \mathrm{E}}$ & $50 \pm 3^{\mathrm{C}, \mathrm{E}}$ & $42 \pm 1^{\mathrm{A}, \mathrm{B}}$ & $44 \pm 1^{\mathrm{A}}$ \\
\hline $\mathrm{DM}^{\mathrm{a}}(\%$, molar $)$ & $48 \pm 1^{\mathrm{A}, \mathrm{E}}$ & $37.2 \pm 0.5^{\mathrm{B}}$ & $43 \pm 4^{\mathrm{A}, \mathrm{D}}$ & $39 \pm 1^{\mathrm{C}}$ & $43 \pm 2^{\mathrm{D}}$ & $42.1 \pm 0.5^{\mathrm{D}}$ & $48.0 \pm 0.2^{\mathrm{E}}$ & $44 \pm 1^{\mathrm{D}}$ \\
\hline $\mathrm{DA}^{\mathrm{a}}(\%$, molar $)$ & $21 \pm 2^{\mathrm{A}}$ & $19 \pm 1^{\mathrm{A}}$ & $17.4 \pm 0.8^{\mathrm{A}, \mathrm{C}}$ & $20 \pm 1^{\mathrm{A}}$ & $11.2 \pm 0.2^{\mathrm{B}}$ & $14 \pm 1^{\mathrm{C}, \mathrm{D}}$ & $22.4 \pm 0.1^{\mathrm{A}}$ & $13 \pm 1^{\mathrm{D}}$ \\
\hline $\begin{array}{l}\text { Neutral sugars (NS) (g/ } \\
100 \mathrm{~g} \mathrm{PEF})^{\mathrm{c}}\end{array}$ & 54.8 & 44.0 & 37.7 & 35.5 & 41 & 39.0 & 49.3 & 46 \\
\hline NS/UA ${ }^{\mathrm{d}}$ (molar ratio) & 1.43 & 1.25 & 0.83 & 0.81 & 1.0 & 0.90 & 1.29 & 1.16 \\
\hline \multirow[t]{3}{*}{ Molecular weight (Da) } & 787,345 & 136,887 & 651,835 & 779,405 & 132,104 & 787,346 & 121,774 & 123,139 \\
\hline & 130,236 & 48,175 & 138,146 & 127,512 & & 127,512 & & \\
\hline & 43,901 & & & & & 35,428 & & \\
\hline$L^{*}(\%)^{\mathrm{a}}$ & $50 \pm 1^{\mathrm{A}}$ & $48.9 \pm 0.3^{\mathrm{B}}$ & $50.6 \pm 0.5^{\mathrm{C}}$ & $39.3 \pm 0.6^{\mathrm{D}}$ & $48.6 \pm 0.4^{\mathrm{B}}$ & $42.1 \pm 0.6^{\mathrm{B}}$ & $40.1 \pm 0.8^{\mathrm{B}}$ & $44.3 \pm 0.3^{\mathrm{B}}$ \\
\hline$a^{* \mathrm{a}}$ & $29.5 \pm 0.7^{\mathrm{A}}$ & $29.9 \pm 0.4^{\mathrm{A}}$ & $35.7 \pm 0.2^{\mathrm{B}}$ & $24.5 \pm 0.2^{\mathrm{C}}$ & $35.5 \pm 0.3^{\mathrm{A}}$ & $27.4 \pm 0.2^{\mathrm{A}}$ & $31.0 \pm 0.4^{\mathrm{D}}$ & $27.0 \pm 0.2^{\mathrm{B}}$ \\
\hline$b^{* \text { a }}$ & $27.6 \pm 0.8^{\mathrm{A}}$ & $31.7 \pm 0.3^{\mathrm{B}}$ & $33.8 \pm 0.2^{\mathrm{A}}$ & $25.3 \pm 0.3^{\mathrm{C}}$ & $33.6 \pm 0.3^{\mathrm{B}}$ & $28.6 \pm 0.1^{\mathrm{B}}$ & $28.7 \pm 0.4^{\mathrm{B}}$ & $28.3 \pm 0.3^{\mathrm{B}}$ \\
\hline
\end{tabular}

${ }^{\text {a }}$ Mean and standard deviations for $n=3$ or $n=10$ for color parameters are reported. Different capital letters as superscripts in a given row indicate significant differences $(p<0.05)$ among results.

b Yield was calculated as $\mathrm{g} / 100 \mathrm{~g}$ of carrot powder (CP).

c Neutral sugars are calculated as the arithmetical difference between Total carbohydrates and Uronic acids.

d Moles of NS were calculated with a weighed mean monosaccharide molar mass of $166.73 \mathrm{~g} / \mathrm{mol}$ considering the typical monosaccharide composition of pectins as well as a NS/UA molar ratio of 1.2 (Basanta et al., 2013).

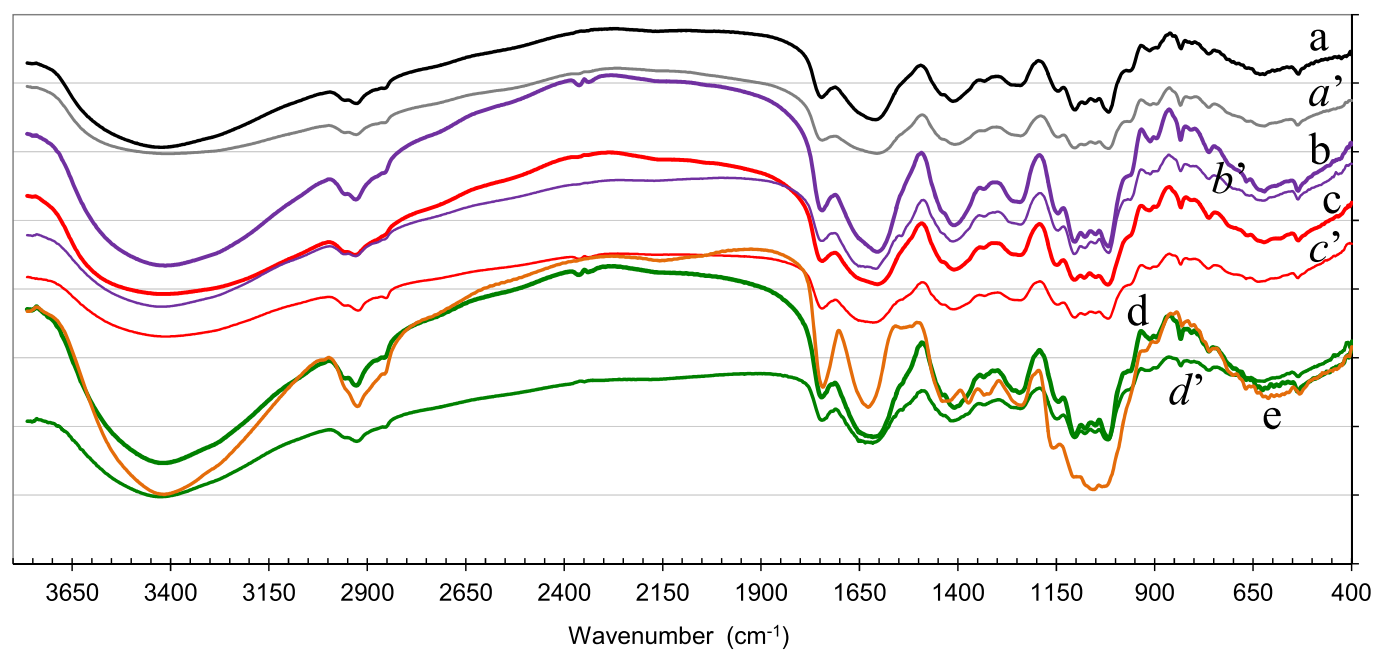

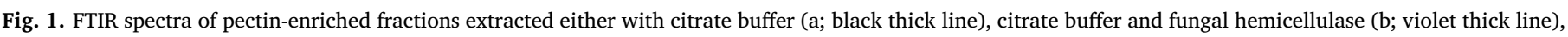

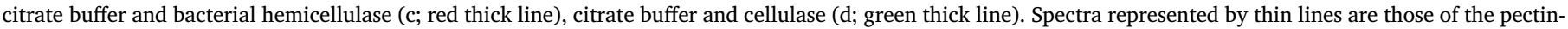

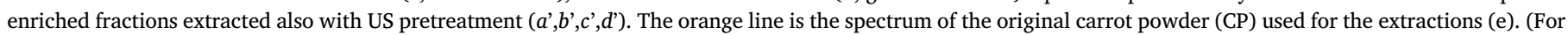
interpretation of the references to color in this figure legend, the reader is referred to the Web version of this article.)

(Fig. 2b). This behavior was also observed in the tangent of delta angle, which increased continuously from above 1 , as habitually observed for viscoelastic liquids. Hence, the hydrated macromolecules of this pectin fraction at $2.00 \% \mathrm{w} / \mathrm{v}$ concentration were not able to interact between them through electrostatic calcium crosslinking in order to constitute the polymeric network of a true gel (Fig. 2). However, this PEF was chemically characterized by the same UA content and similar DM and DA that the US-pretreated fungal hemicellulase extracted fraction, as well as by the same lowest NS/UA molar ratio (Table 2). The acetylation of the UA residues of pectin HG can hinder the interactions between macromolecules for calcium crosslinking and gelling (May, 1990 ), and hence it may decrease $G^{\prime}$ values. More than nine contiguous calcium bridges are required to generate a stable connection between demethylated HG blocks of neighbor pectin macromolecules (Vincken et al., 2003). Consequently, the US-pretreatment favored the extraction of PEFs sensible to calcium ions, hence, with demethylated HG blocks of enough length, and with the best rheological performance. The most rigid gel (less frequency dependent in $G^{\prime}$ and $G^{\prime \prime}$ ) was that developed by the US-pretreated PEF extracted with citrate buffer without enzyme (Fig. 2a), which in addition showed the highest value of $G^{\prime}(761 \mathrm{~Pa})$. The rest of the US-pretreated PEFs developed gels with lower values of $G^{\prime}$ ( $\approx 470 \mathrm{~Pa}$ for fungal and bacterial hemicellulase, and $240 \mathrm{~Pa}$ for cellulase extracted PEF) (Fig. 2 b-d). Enzymes were then needed to produce PEFs with different rheological performance to that of the USpretreated buffer extracted fraction and, hence, with different textures.

The UA contents of all PEFs isolated in the present work were similar between the non-treated and the corresponding US-pretreated fractions. The DM was lower for the US-pretreated fractions obtained 

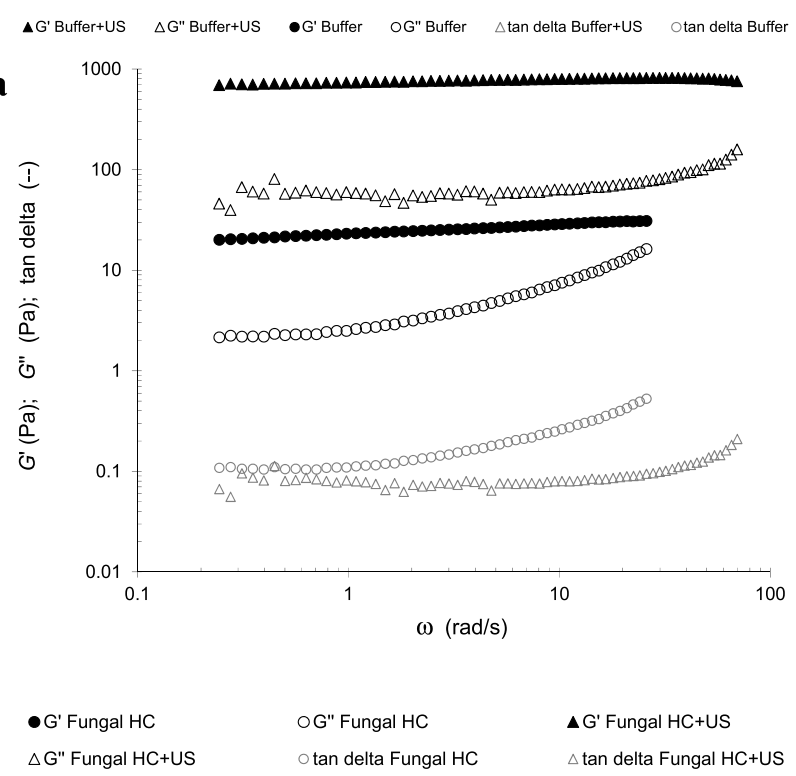

b

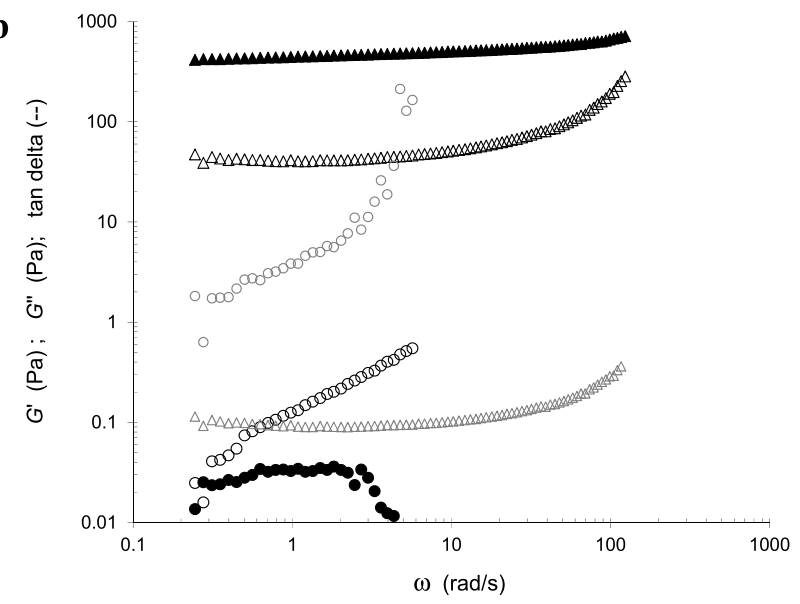

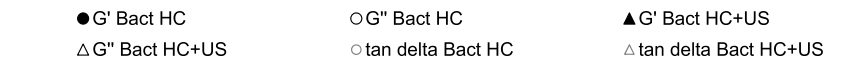

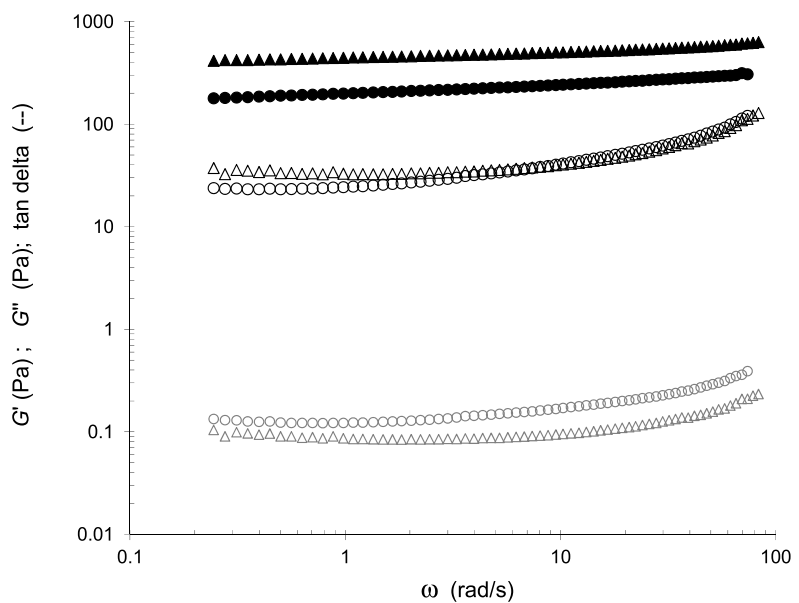

- G' Ind cellulase $\quad O G$ " Ind cellulase $\quad \Delta G^{\prime}$ Ind cellulase+US

$\triangle G^{\prime \prime}$ Ind cellulase+US $\quad \Delta$ tan delta Ind cellulase+US $\quad$ tan delta Ind cellulase

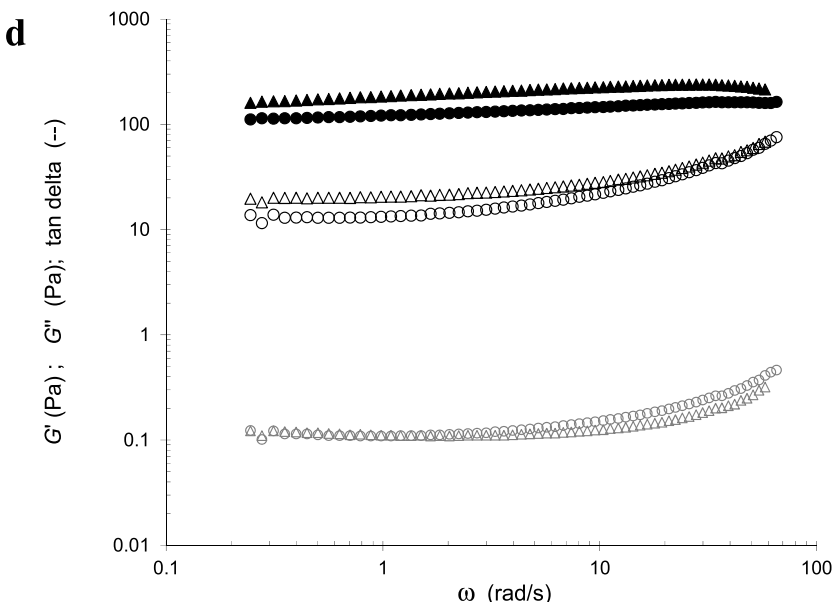

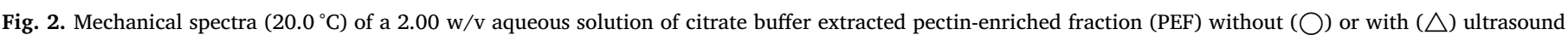

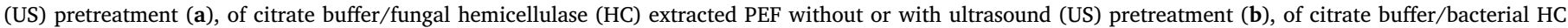

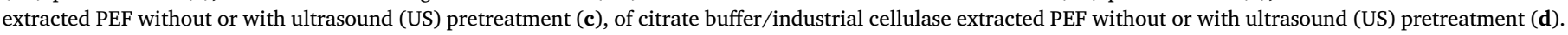
Black filled symbols, G'; black empty symbols, G'; gray empty symbols, tangent of the phase angle (tan delta).

through citrate buffer, fungal hemicellulase, and cellulase than the corresponding DM of the non-US treated fraction (Table 2). Lower NS/ UA molar ratios were also observed for the US-pretreated fractions obtained with citrate buffer or cellulase, but the ratios were similar for the PEFs obtained through hemicellulases, with and without US-pretreatment. The molecular weight profiles of the PEFs obtained through cellulase assisted extraction were of the same order. On the other hand, the non-US pretreated citrate buffer extracted fraction, which produced a less structured gel and with notably lower $G^{\prime}$ value ( $\approx 25 \mathrm{~Pa}$; Fig. $2 \mathrm{a}$ ), showed an additional macromolecular component of high molecular weight $(787,345 \mathrm{Da})$ to those observed for the corresponding US-pretreated fraction (Table 2). Therefore, the lower DM and the NS/UA molar ratio, together with the molecular weight profile of 137,000-121,000 Da and 43,901-48,175 Da (Table 2) can probably contribute to the higher $G^{\prime}$ value and structuration of gels showed by both US-pretreated fractions (Fig. 2 a,d). On the contrary, the molecular weight profiles of the non-US and US-pretreated bacterial hemicellulase extracted fraction showed that the additional presence of a macromolecular component of higher molecular weight $(787,346 \mathrm{Da}$; Table 2) contributed to a better performance of a gel with some higher $G^{\prime}$ value (472 Pa against $219 \mathrm{~Pa}$; Fig. 2c). Similar molecular weight profiles were shown by the non-US and US-pretreated fungal hemicellulase PEFs (Table 2). These four fractions extracted through bacterial or fungal hemicellulase were also characterized by their lowest NS/UA molar ratios (0.81-1.0; Table 2). Probably, differences in the patterns of demethylated blocks' distribution in the HGs could be the fact that justified their respective and different rheological performances (Hotchkiss et al., 2002). For fungal hemicellulase and citrate buffer extraction procedures, the US-pretreatment was essential to obtain PEFs with good rheological performance as gelling agent.

\subsubsection{Co-extracted fat-soluble compounds}

$\alpha$-carotene, $\beta$-carotene, lutein and $\alpha$-tocopherol were found in these fractions. The $\alpha$ - and $\beta$-carotene contents were in the order of 12 and $17 \mathrm{mg}$ per $100 \mathrm{~g}$ of PEF (dry basis), respectively (Fig. 3a). Lutein and $\alpha$ tocopherol were also co-extracted in amounts that varied between 0.4 and $0.75 \mathrm{mg} / 100 \mathrm{~g}$ of PEF for lutein, and 1.0 and $1.6 \mathrm{mg} / 100 \mathrm{~g}$ for the $\alpha$-tocopherol (Fig. 3b). Co-extracted carotenes were then responsible for the orange color of the PEFs, which was characterized by the color parameters $\left(a^{*}, b^{*}\right)$ reported in Table 2 . They varied between +25.0 and +35.7 for $a^{*}$, or +27.6 and +33.8 for $b^{*}$. The orange color was dark as demonstrated by the lightness $\left(L^{*}\right)$ values, which varied between 39.3 and $50.6 \%$ (Table 2). 

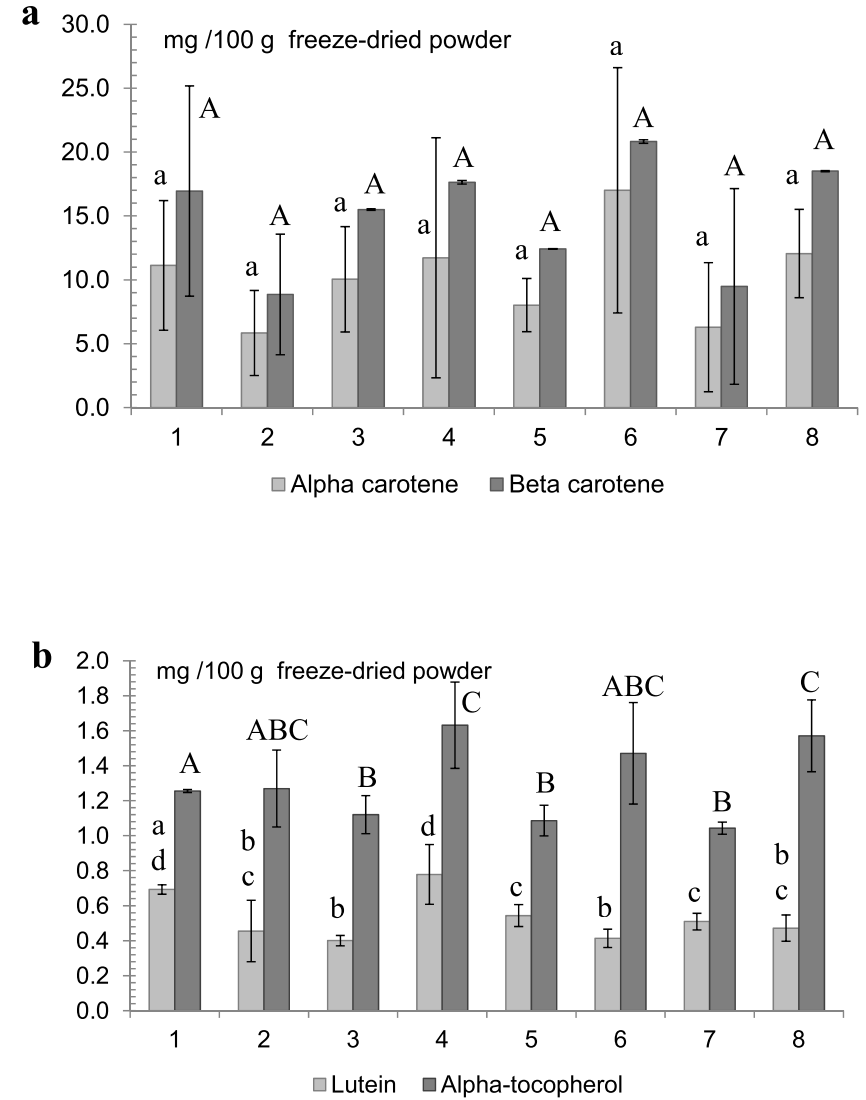

Fig. 3. Contents of fat-soluble compounds found in the pectin-enriched fractions extracted either with citrate buffer without (1) or with ultrasound pretreatment, US (2), citrate buffer and fungal hemicellulase without (3) or with US (4), citrate buffer and bacterial hemicellulase without (5) or with US (6), citrate buffer and cellulase without (7) or with US (8). Error bars are the standard deviations for $n=3$. The same lower case or upper case letters for a given compound indicate non-significant differences $(p<0.05)$.

\section{Conclusions}

Orange-colored PEFs with relevant functional properties were obtained with $\approx 20 \%$ of yield from the sugar-exhausted blanched powder (CP) of discarded carrots, through an extractive process with a USpretreatment of $12.27 \mathrm{~W} / \mathrm{cm}^{2}$ power intensity followed by stirring in citrate buffer ( $\mathrm{pH} 5.20$ ), either without or with an industrial enzyme. Fungal and bacterial hemicellulases and cellulase were used, which are habitually commercialized for hydrolysis of pentosans in wheat dough. The PEFs obtained were characterized by UA contents between 39 and $51 \%$ with low DM (37.2-48\%) and an important DA (11-22\%), and a predominant $121,000-138,000 \mathrm{Da} \mathrm{Mw}$ range. All PEFs contained coextracted $\alpha$ - and $\beta$-carotenes, lutein and $\alpha$-tocopherol, being the carotenes responsible for their orange color. Only the use of fungalhemicellulase without US-pretreatment produced a significant increase in the yield of the PEF obtained (10.4\%), in comparison to the non-US pretreated citrate buffer extracted pectins (6.9\%). The US-step was which decisively led to high yields in the PEFs' extraction $(\approx 20 \%)$, while there was not additional contribution of the industrial enzymeactivities. However, the enzymes allowed obtaining PEFs with different gel and then textural characteristics in the calcium presence. US-pretreated PEFs showed the best rheological performance, constituting more structured true gels by calcium crosslinking, and with higher elastic $\left(G^{\prime}\right)$ modulus than non-ultrasound extracted fractions. Carrots residues were upgraded as PEFs useful as functional gelling additives for food formulation by using a green extractive and efficient process.

\section{Acknowledgements}

Authors are grateful to the financial support of Universidad de Buenos Aires [UBACyT 2014-2017 20020130100553BA], ANPCyT [PICT 2013-2088, 2015-2109], and INTA [9.2013.5.39-2189398, PNPA 1126044]. We thank Lic. Julia García Callegari and Priscila Porto, Bio Aba S.A., for providing us the baking enzymes from DSM (Netherlands).

\section{References}

Alessandro, M. S., Lopez Frasca, A., \& González, M. (2014). Evaluación de cultivares de zanahoria en el Valle de Uco, Mendoza. Horticultura Argentina, 33(81), 22-30.

Basanta, M. F., de Escalada Pla, M. F., Stortz, C. A., \& Rojas, A. M. (2013). Chemical and functional properties of cell wall polymers from two cherry varieties at two developmental stages. Carbohydrate Polymers, 92, 830-841.

Broxterman, S. E., Picouet, P., \& Schols, H. A. (2017). Acetylated pectins in raw and heat processed carrots. Carbohydrate Polymers, 177, 58-66.

Ciriminna, R., Fidalgo, A., Delisi, R., Ilharco, L. M., \& Pagliaro, M. (2016). Pectin production and global market. Agro Food Industry Hi-Tech, 27(5), September https:// www.teknoscienze.com/tks_article/pectin-production-and-global-market/, Accessed date: 22 September 2018 .

Dansa, A. M., Bougardt, F., \& Nocera, P. (2017). Perfil del mercado de zanahoria. Ministerio de Agroindustriahttps://www.agroindustria.gob.ar/sitio/areas/ss mercados agropecuarios/areas/hortalizas/_archivos/000030_Informes/000996_Perfil\%20del \%20Mercado\%20de\%20Zanahoria\%202017.pdf, Accessed date: 13 October 2018.

Fissore, E. N., Ponce, N. M. A., Stortz, C. A., Rojas, A. M., \& Gerschenson, L. N. (2007). Characterization of fiber obtained from pumpkin (Cucumis moschata Duch.) mesocarp through enzymatic treatment. Food Science and Technology International, 16(1), 1-7.

Fissore, E. N., Rojas, A. M., Gerschenson, L. N., \& Williams, P. A. (2013). Butternut and beetroot pectins: Characterization and functional properties. Food Hydrocolloids, 31, $172-182$.

Freitas de Oliveira, C., Giordani, D., Lutckemier, R., Gurak, P., Cladera-Olivera, F., \& Ferreira Marczak, L. (2016). Extraction of pectin from passion fruit peel assisted by ultrasound. LWT- Food Science and Technology, 71, 110-115.

Hotchkiss, A. T., Savary, B. J., Cameron, R. G., Chau, H. K., Brouillette, J., Luzio, G. A., et al. (2002). Enzymatic modification of pectin to increase its calcium sensitivity while preserving its molecular weight. Journal of Agricultural and Food Chemistry, 50(10), 2931-2937.

Idrovo Encalada, A. M., Basanta, M. F., Fissore, E. N., De'Nobili, M. D., \& Rojas, A. M. (2016). Carrot fiber (CF) composite films for antioxidant preservation: Particle size effect. Carbohydrate Polymers, 136, 1041-1051.

Liew, S. Q., Ngoh, G. C., Yusoff, R., \& Teoh, W. H. (2018). Acid and deep eutectic solvent (DES) extraction of pectin from pomelo (Citrus grandis L. Osbeck) peels. Biocatalysis and Agricultural Biotechnology, 13, 1-11.

Mamvura, T. A., Iyuke, S. E., \& Paterson, A. E. (2018). Energy changes during use of highpower ultrasound on food grade surfaces. South African Journal of Chemical Engineering, 25, 62-73.

May, C. D. (1990). Industrial pectins: Sources, production and applications. Carbohydrate Polymers, 12, 79-99.

Munarin, F., Bozzini, S., Visai, L., Tanzi, M. C., \& Petrini, P. (2013). Sterilization treatments on polysaccharides: Effects and side effects on pectin. Food Hydrocolloids, 31(1), 74-84.

Ng, A., Parr, A. J., Ingham, L. M., Rigby, N. M., \& Waldron, K. W. (1998). Cell wall chemistry of carrots (Daucus carota Cv. Amstrong) during maturation and storage. Journal of Agricultural and Food Chemistry, 46, 2933-2939.

Purcell, J. M., \& Fishman, M. L. (1987). Dissociation of dissolved pectins: Fourier-transform infrared spectroscopy. Carbohydrate Research, 159, 185-190.

Puri, M., Sharma, D., \& Barrow, C. (2012). Enzyme-assisted extraction of bioactives from plants. Trends in Biotechnology, 30, 37-44.

Rosicka-Kaczmarek, J., Komisarczyk, A., \& Nebesny, E. (2018). Heteropolysaccharide preparations from rye and wheat bran as sources of antioxidants. Journal of Cereal Science, 81, 37-43.

Rossetti, L., Langman, L., Grigioni, G. M., Biolatto, A., Sancho, A. M., Comerón, E., et al. (2010). Antioxidant status and odor profile in milk from silage or alfalfa-fed cows. Australian Journal of Dairy Technology, 65, 3-9.

Santos, H. M., Lodeiro, C., \& Capelo-Martínez, J. L. (2009). The power of ultrasound. In J. L. Capelo-Martínez (Ed.). Ultrasound in chemistry: Analytical applications (pp. 1-16). Weinheim: Wiley VCH.

Stuart, T. (2009). Part II. Squandered harvests. Farming: Potatoes have eyes. In T. Stuart (Ed.). Waste: Uncovering the global food scandal (pp. 104). New York-London: W.W. Norton \& Company.

Synytsya, A., Copikova, J., \& Jankovska, P. (2003). Spectroscopic estimation of feruloyl groups in sugar beet pulp and pectin. International Sugar Journal, 105, 481-488.

Van Buggenhout, S., Sila, D. N., Duvetter, T., Van Loey, A., \& Hendrickx, M. (2009). Pectins in processed fruits and vegetables: Part III - texture engineering. Comprehensive Reviews in Food Science and Food Safety, 8, 105-117.

Vincken, J. P., Schols, H. A., Oomen, R. J. F. J., McCann, M. C., Ulvskov, P., Voragen, A. G. J., et al. (2003). If homogalacturonan were a side chain of rhamnogalacturonan I. Implications for cell wall architecture. Plant Physiology, 132, 1781-1789. 